\title{
Imaging the Internal Structure of an Alpine Glacier via L-Band Airborne SAR Tomography
}

\author{
Stefano Tebaldini, Thomas Nagler, Member, IEEE, Helmut Rott, Fellow, IEEE, and Achim Heilig
}

\begin{abstract}
In this paper, we report results from the analysis of 3-D L-band airborne synthetic aperture radar (SAR) acquisitions acquired in March 2014 over the Mittelbergferner glacier, Austrian Alps, during the European Space Agency (ESA) campaign AlpTomoSAR. The campaign included coincident in situ measurements of snow and ice properties and ground-penetrating radar (GPR) data acquired at 600 and $200 \mathrm{MHz}$ over a total length of $18 \mathrm{~km}$. Radar data were acquired by repeatedly flying an L-band SAR along an oval racetrack at an altitude of about $1300 \mathrm{~m}$ over the glacier, such that two data stacks from opposite views are obtained. Data from all passes were coherently combined to achieve 3-D resolution capabilities, resulting in the generation of 3-D tomographic SAR (TomoSAR) cubes, where each voxel represents $L-b a n d$ radar reflectivity from a particular location in the 3-D space at a spatial resolution on the order of meters. TomoSAR cubes were finally corrected to account for wave propagation velocity into the ice, which was a necessary step to associate the observed features with their geometrical location, hence enabling a direct comparison to GPR data. The TomoSAR cubes show the complexity of the glacier subsurface scattering. Most areas are characterized by surface scattering in proximity of the ice surface, plus a complex pattern of in-depth volumetric scattering beneath and scattering at the ice/bedrock interface. Various subsurface features observed in GPR transects at $200 \mathrm{MHz}$ clearly showed up in TomoSAR sections as well, particularly firn bodies, crevasses, layer transitions, and bedrock reflection down to $50 \mathrm{~m}$ below the ice surface.
\end{abstract}

Index Terms-Airborne radar, electromagnetic tomography, ground-penetrating radar (GPR), synthetic aperture radar (SAR), tomography.

\section{INTRODUCTION}

$\mathbf{S}$ YNTHETIC aperture radar (SAR) is nowadays a most relevant technology for remote sensing of natural environment. This prominent position is the result of the combination of

Manuscript received December 2, 2015; revised June 17, 2016; accepted July 27, 2016. Date of publication August 29, 2016; date of current version September 30, 2016.

$\mathrm{S}$. Tebaldini is with the Department of Electronics, Information, and Bioengineering, Politecnico di Milano, 20133 Milano, Italy (e-mail: tebaldini@ elet.polimi.it).

T. Nagler is with Environmental Earth Observation Information Technology (ENVEO IT) GmbH, 6020 Innsbruck, Austria.

H. Rott is with Environmental Earth Observation Information Technology (ENVEO IT) GmbH, 6020 Innsbruck, Austria and also with the Institute of Atmospheric and Cryospheric Sciences, University of Innsbruck, 6020 Innsbruck, Austria.

A. Heilig was with the University of Heidelberg, 69117 Heidelberg, Germany, and also with the WSL Institute for Snow and Avalanche Research SLF, 7260 Davos Dorf, Switzerland. He is now with the Ludwig Maximilian University of Munich, 80539 Munich, Germany. different features, such as large spatial coverage, resolution on the order of few meters, and the possibility to operate largely independently on weather conditions and solar illumination. Moreover, at the microwave regime, electromagnetic waves are capable of penetrating into natural media that are nontransparent at optical frequencies, e.g., snow, ice, and sand. This feature makes SAR data sensitive to the vertical structure of those media, hence providing a substantial advantage over optical sensors. The downside is that microwave scattering from distributed media may be quite complex, involving a number of different scattering mechanisms. Considering ice, which is the focus of this paper, signal backscatter is expected to arise from air/ice or snow/ice interface scattering, scattering from subsurface targets, bedrock, interfaces of layers with different dielectric permittivity, and eventually multiple scattering. This offers the opportunity to observe the internal structure of glaciers and polar ice sheets, which is of fundamental importance for glacier dynamics and mass balance, for understanding and modeling the water movement through a glacier, and for assessing the response of the ice masses to climate forcing [1]-[3]. Airborne or in situ ground-penetrating radar (GPR) sensors are commonly used for detecting the internal structure of glaciers and ice sheets, e.g., [4]-[6]. Whereas these sensors are deployed on a campaign basis, satelliteborne SAR is able to provide complete and regular coverage of the global land ice masses. In the literature, various experimental studies have been presented that are reporting on retrievals of bulk properties of glacial snow and firn volumes from polarimetric and interferometric SAR images [1]-[3], [7].

In this paper, we report results on a direct 3-D measurement of the radar reflectivity within the glacier volume, which is obtained by 3-D focusing of multiple SAR acquisitions gathered from slightly different points of view. This approach, which is commonly referred to as tomographic SAR (TomoSAR) imaging, has been largely considered in recent years for forestry applications because it entails a fundamental advantage over traditional (i.e., 2-D) SAR imaging, namely, the possibility to see the vertical structure of the imaged volume, to be afterward employed as a robust basis for validation and development of physical models [8]-[15].

The data set was acquired during the AlpTomoSAR campaign, which was supported by the European Space Agency (ESA) as a part of activities related to the SAR Observation and Communications Companion Satellite (SAOCOM-CS) mission [16]. The campaign was carried out in February/March 2014 over the Mittelbergferner glacier, Austrian Alps. SAR data were acquired by repeatedly flying an L-band SAR along an oval racetrack, in order to collect two data stacks from opposite 


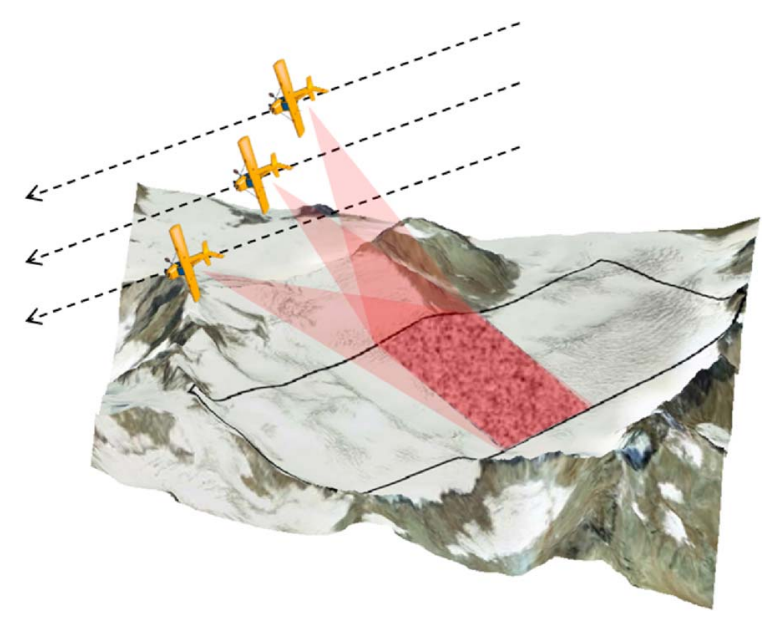

Fig. 1. TomoSAR experiment.

views. Tomographic processing was then applied to focus data from each view in the 3-D space.

AlpTomoSAR is not the first airborne tomographic data set acquired over ice. A P-band airborne tomographic experiment was carried out using the POLARIS system, flown by the Technical University of Denmark (DTU), in 2012, in Western Greenland [4]. Results from an L-band data set acquired over Svalbard have recently been reported in [5], in the frame of Tandem-L studies. The added value of this paper results from the combination of different factors. One factor is the presence of a deep penetration into the glacier ice body, allowing to detect a clear signature from the bedrock about $50 \mathrm{~m}$ below the ice surface. Another factor is the unprecedented vertical resolution for this kind of application, which is enabled by flight planning and the employment of fully 3-D focusing techniques. A final factor is the availability of coincident in situ measurements of snow and ice properties and GPR data acquired at 600 and $200 \mathrm{MHz}$ over a total length of $18 \mathrm{~km}$. These characteristics have enabled to detect a number of subsurface features, to observe their spatial structure, and to provide a clear interpretation by direct comparison to in situ measurements (mostly from GPR).

This paper is organized in six sections. In Section II, the principles of TomoSAR imaging are presented. The acquisition campaign is reported in Section III. The generation of TomoSAR cubes is discussed in Section IV. Results are presented and discussed in Section V. Finally, conclusions are drawn in Section VI.

\section{TOMOGRAPHIC IMAGING}

The expression TomoSAR is generally used to indicate a microwave imaging technology to focus the illuminated scatterers in the 3-D space by processing data from multiple SAR acquisitions [8], [17], as shown in Fig. 1. This technique has received increasing attention in the last years by different research groups, including application fields, such as 3-D urban reconstruction and monitoring [18], [19], forestry [10], [12], [13], 3-D analysis of snowpack [20], ice sheets [4], [5], and glaciers [14], [15]. The rationale of this technique is easily understood by considering that the availability of multiple observations allows the formation of a 2-D synthetic aperture.

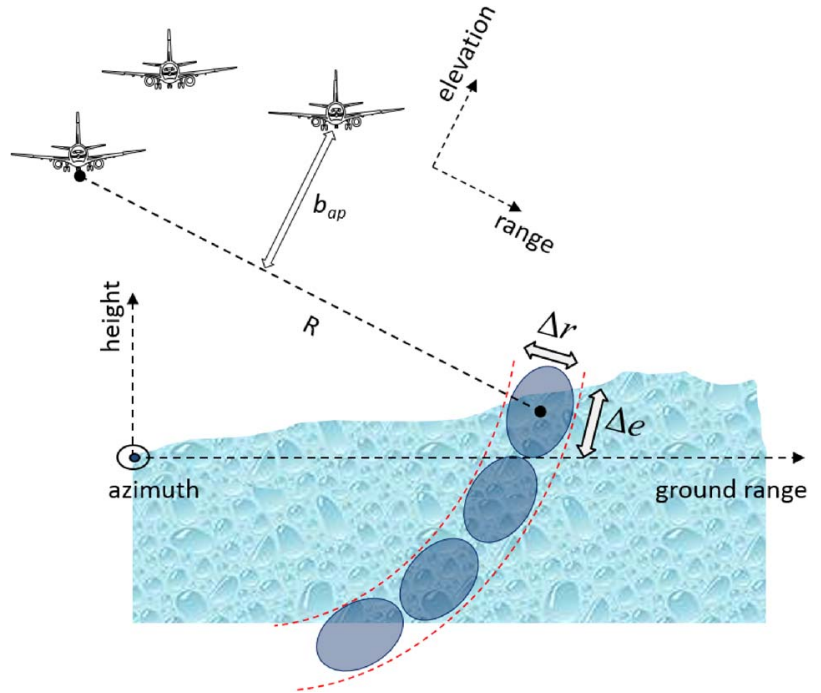

Fig. 2. TomoSAR geometry in the height/ground range plane. The bluish balloons indicate the geometrical extent of the tomographic voxel.

Accordingly, the gathered radar echoes can be focused not only in the range-azimuth plane, as in conventional 2-D SAR imaging, but also in elevation.

A sketch of this concept is shown in Fig. 2. The SAR resolution cell is split along elevation into several tomographic resolution cells. The geometrical resolution in the range and azimuth direction is the same as conventional 2-D SAR, i.e.,

$$
\begin{aligned}
& \Delta r=\frac{c}{2 B} \\
& \Delta x=\frac{\lambda}{2 L_{s}} R
\end{aligned}
$$

where $r$ and $x$ indicate range and azimuth, respectively; $c$ is the wave velocity in vacuum; $B$ is the pulse bandwidth; $\lambda$ is the carrier wavelength; $L_{s}$ is the synthetic aperture length (in azimuth); and $R$ is the stand-off distance from the imaged target. Resolution in elevation depends on the total length of the synthetic aperture in elevation, which is usually referred to as baseline aperture [8]. In formula

$$
\Delta e=\frac{\lambda}{2 b_{\mathrm{ap}}} R
$$

where $e$ indicates elevation, and $b_{\text {ap }}$ is the total baseline aperture. Vertical resolution is roughly obtained as $\Delta z \simeq \Delta e \cdot \sin \theta$, where $\theta$ indicates the incidence angle [21].

In addition to resolution, the quality of tomographic imaging is significantly determined by the actual baseline distribution, which is the set of relative positions among the flights. Strongly irregular baseline distributions are well known to result in sidelobe phenomena, hindering image interpretation [22]-[24].

A large variety of processing approaches can be found in literature. In most previous experiments, tomographic imaging was carried out by decoupling focusing in the range-azimuth plane from focusing in elevation. This approach allows to cast tomographic processing in terms of a 1-D spectral estimation problem, where the vector obtained by taking a pixel in the data stack corresponding to a fixed range-azimuth location is transformed into a reflectivity distribution in elevation. This 
processing approach enables the employment of signal processing techniques developed in the Direction of Arrival (DOA) domain, which provide enhanced resolution capabilities and sidelobe rejection [12], [21], [24], [25]. In the case of high 3-D resolution data, however, a relative range and azimuth cell migration is expected to occur from one pass to another. In this case, tomographic processing needs to be carried out in all three dimensions at the same time [26]-[28]. This is the case for the AlpTomoSAR data set presented in this paper.

Finally, a fundamental requirement to enable 3-D data focusing from repeat pass data is that the knowledge about the antenna phase center position in all flights is accurate enough to predict variations of the distance traveled by the wave to within an accuracy much better than the system wavelength. The location accuracy of navigational systems is usually adequate to correctly predict the distance variation over a synthetic aperture along a single flight line, thus ensuring correct signal focusing in the 2-D space. However, it might fail to provide the required subwavelength accuracy concerning the location of one flight line with respect to another. This results in focused SAR images to be affected by space-varying phase disturbances, which are commonly referred to as phase screens [29], [30]. Such phase screens may easily turn out to be critical for TomoSAR imaging, possible effects ranging from sidelobes to complete defocusing [30]. For this reason, TomoSAR data sets require quite often a preprocessing phase calibration step [31].

\section{ACQUISITION CAMPAIGN}

Mittelbergferner is, on average, a mostly northerly exposed temperate glacier in the Ötztal Alps, covering approximately $9 \mathrm{~km}^{2}$ in area and spanning from $\sim 2500$ to $\sim 3500 \mathrm{~m}$. An oblique photograph of the glacier, which was recorded during the airborne campaign, is shown in Fig. 3. The western part of the Mittelbergferner is developed by the Pitztaler Gletscher skiing area, whereas the bigger easterly part is chosen as the test site (approximately $5.5 \mathrm{~km} \times 2.3 \mathrm{~km}$; from $\sim 2800$ to $\sim 3250 \mathrm{~m}$ ). Due to the warm and humid summers during the last decade, the equilibrium line altitude was often close to the highest parts of the glacier. Thus, the firn body was reduced to its highest basins. The test site was also investigated during the AlpSAR campaign using a number of techniques, including $\mathrm{X}$ - and $\mathrm{Ku}$-band airborne radar surveys, firn temperature probes, snow-depth transects, and snow pit measurements [32], [33].

The campaign was started on February 26 and concluded on March 11, 2014. The flight campaign took place on the morning of March 7, 2014, taking advantage of clear sky conditions. The mean air temperature at $3000 \mathrm{~m}$ was $-6.4^{\circ}$. The mean temperature of the seasonal (winter) snow cover on the glacier was $-12^{\circ}$. Snow measurements were carried out on March 6 and March 11, 2014. GPR data were acquired on February 27 and 28, 2014.

\section{A. SAR Acquisitions}

SAR data were acquired using a fully polarimetric frequencymodulated continuous-waveform L-band SAR by MetaSensing. The system was operated at a central frequency of $1275 \mathrm{MHz}$, with a pulse bandwidth of $150 \mathrm{MHz}$. The aircraft used for SAR

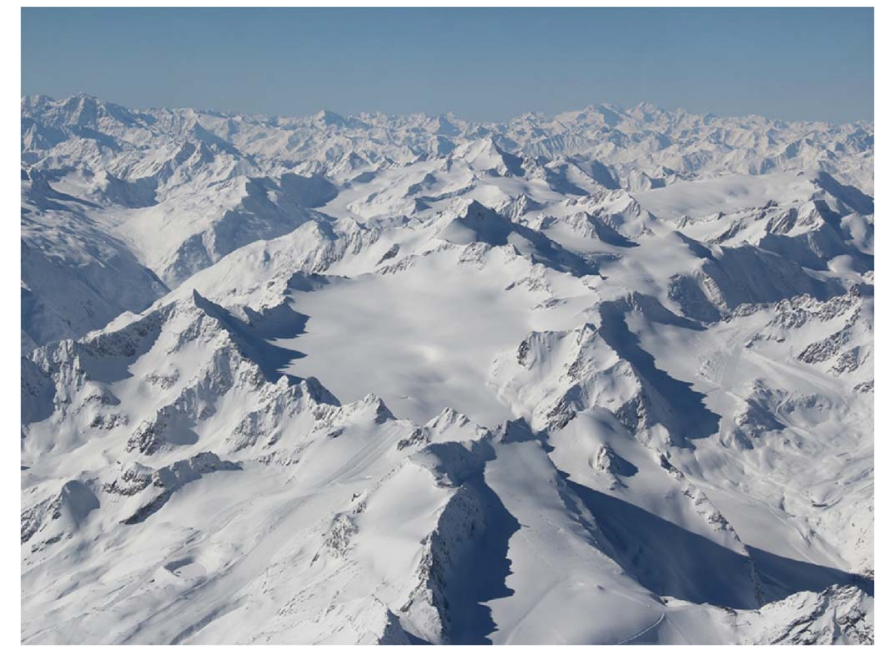

Fig. 3. Aerial photograph of the Mittelbergferner glacier, recorded during the airborne campaign on March 7, 2014.

acquisitions was a CASA C-212, a twin-turboprop-powered medium transport aircraft operated by the Italian company CGR Spa. The flight lines were designed to have ten parallel and closely spaced tracks (1-m horizontal baseline) plus other more largely spaced tracks to improve resolution. The aircraft was flown along an oval racetrack configuration, to provide two independent data sets from two opposite views. Flight altitude was about $4500 \mathrm{~m}$, which is roughly $1300 \mathrm{~m}$ above the illuminated scene. As expected, flight trajectories have been perturbed by turbulent phenomena in proximity of the peaks. The standard deviation of the flight trajectories is assessed in about $13 \mathrm{~m}$ and $1 \mathrm{~m}$ in the horizontal and vertical direction, respectively. In both views, the total baseline aperture resulted in a vertical resolution of approximately $2 \mathrm{~m}$. Raw data from all the passages have been focused through time-domain back projection (TDBP). This approach has been chosen despite the high computational burden, as it allows to 1) perfectly cope with platform deviations from the nominal straight trajectories; 2) focus the raw data by retaining the same horizontal wavenumbers in all passages, preserving the interferometric coherence; 3 ) jointly focus and geocode all tracks on the same reference surface, ensuring image coregistration. The reference surface was derived from a Lidar Digital Terrain Model (DTM) of the Mittelbergferner acquired in 2010. The spatial resolution of focused 2-D singlelook complex (SLC) images is approximately $2 \mathrm{~m} \times 1.5 \mathrm{~m}$ (ground range and azimuth). Figs. 4 and 5 show maps of the resulting 2-D SAR intensities.

\section{B. Field Work}

For supporting the L-band TomoSAR acquisitions, the following field measurements were performed:

- manual snow probings along transects to assess the depth of the winter snow accumulation;

- conventional snow pits;

- in situ GPR measurements covering a large part of the glacier (in total $18 \mathrm{~km}$ );

- installation of trihedral corner reflectors at the snow surface. 

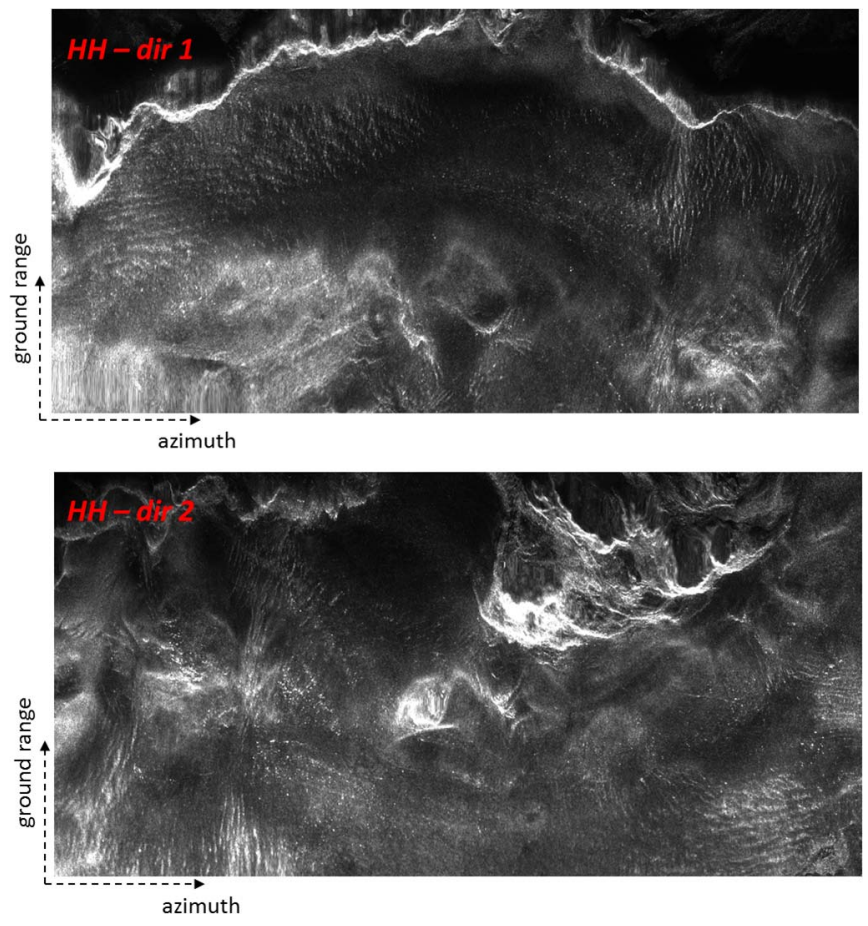

Fig. 4. 2-D SAR intensity maps in SAR geometry acquired from the two opposite views. Polarization: $\mathrm{HH}$.
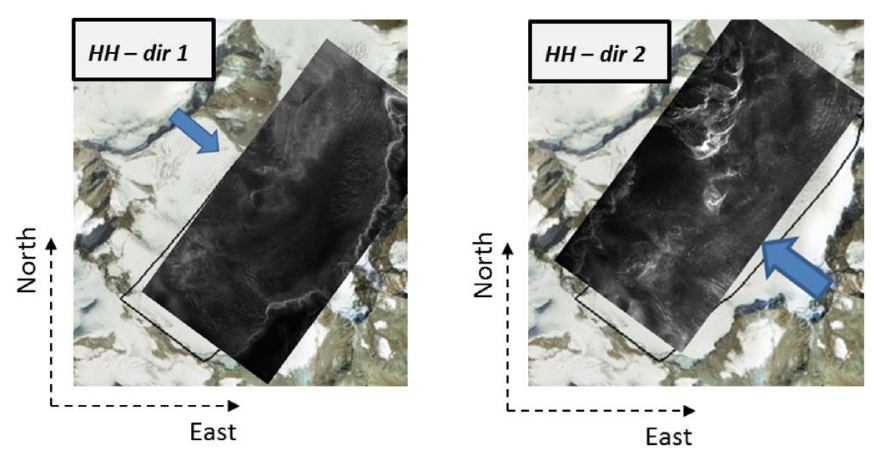

Fig. 5. Geocoded 2-D SAR intensity maps acquired from the two opposite views. Polarization: HH. The blue arrows indicate the radar line of sight in the two views.

1) Snow-Depth Transects: Ground-based measurements of snow depth were carried out along the longitudinal and cross profiles covering most parts of the investigation area. Several crevasse zones cross the glacier, which required shifting the paths accordingly. Snow-depth measurements along the transects were performed about every $100 \mathrm{~m}$. At each location, five snow-depth measurements were taken using an avalanche probe. Additionally, the center location was measured with GPS. The average measured snow depths recorded on March 6, 2014, are shown in Fig. 6, with the same color code as the GPR-derived snow depths.

2) Conventional Snow Pits: Vertical profiles of physical snow parameters of the winter snowpack were measured in snow pits at various locations on the glacier. Vertical profiles of the following parameters were measured for each layer or for regular steps: stratigraphy, snow density, grain size, snow hardness, and snow temperature (at various snow depths). Snow density was determined by weighing the mass of snow samples of a defined volume $\left(500 \mathrm{~cm}^{3}\right)$ in cylinders $(20-\mathrm{cm}$ length with respective diameter). In addition, the snow grains were photographically documented. We recorded an average density of about $380 \mathrm{~kg} \cdot \mathrm{m}^{-3}$ and snow temperatures well below $0{ }^{\circ} \mathrm{C}$ for all snow pits. On average, the winter snowpack showed a uniform thickness between 210 and $300 \mathrm{~cm}$ and can be considered as being dry. Except for a bottom layer of about $30 \mathrm{~cm}$ containing coarse-grained refrozen snow, the snowpack was fine grained, with grain sizes $\leq 1 \mathrm{~mm}$. For such snow type, scattering at L-band frequencies is negligible.

3) GPR Surveys: Ground-based GPR data were acquired along transects over a total length of about $18 \mathrm{~km}$, as shown in Fig. 6. From the GPR data, we derived information on the vertical structure and layering of winter snow and the underlying ice body of the glacier down to the maximal 50-m depth in ice. The acquisition was carried out using a dual-frequency system by Ingegneria dei Sistemi (IDS) operating at 600 and $200 \mathrm{MHz}$, which was connected to a GPS receiver for geolocation of the GPR transect. The measured quantity is the reflected amplitude in dependence of the two-way travel time (TWT). If medium properties are known, then TWT can be converted to depth. In dry-snow conditions, velocity of propagation of electromagnetic waves for the applied frequency ranges depends solely on density [34]. For the snow-depth calculations in Fig. 6, we used the average bulk snow density recorded in the snow pits. For firn, density and, in the case of wet firn, liquid water content are needed for accurate determination of the depth of specific layers. For an approximate calculation of radar wave velocity, ice can be regarded as a homogeneous medium, and standard values for the dielectric relative permittivity can be assumed [35]-[37].

4) Corner Reflectors: Field works have also included deployment, maintenance, and dismantlement of eight trihedral corner reflectors, which were manufactured by MetaSensing (square reflectors) and ARESYS (triangular reflectors with honeycomb faces). The purpose of installing those reflectors was to have a clear signal from the top of the snowpack, whereas absolute radiometric calibration was not considered as one of the scopes of the campaign. For this reason, the reflectors have been prepared favoring aspects, such as lightness and easiness of transportation, and deployed directly on the snow cover (see Fig. 7). The eight reflectors were set up in pairs, at four different locations, so as to be visible from the two opposite views.

\section{TOMOSAR CUBES}

Tomographic processing consisted in jointly focusing, in the 3-D space, all flights for each view and for each polarization. This resulted in the generation of eight SLC 3-D data cubes, which will be hereinafter referred to as TomoSAR cubes. All cubes were generated using ground coordinates. The horizontal coordinates of each cubes correspond to ground range and azimuth. The vertical coordinate corresponds to height with respect to the Lidar DTM, entailing that Lidar surface height corresponds to the height coordinate $z=0$ in TomoSAR cubes. The decision to use the Lidar DTM as reference, despite the fact 

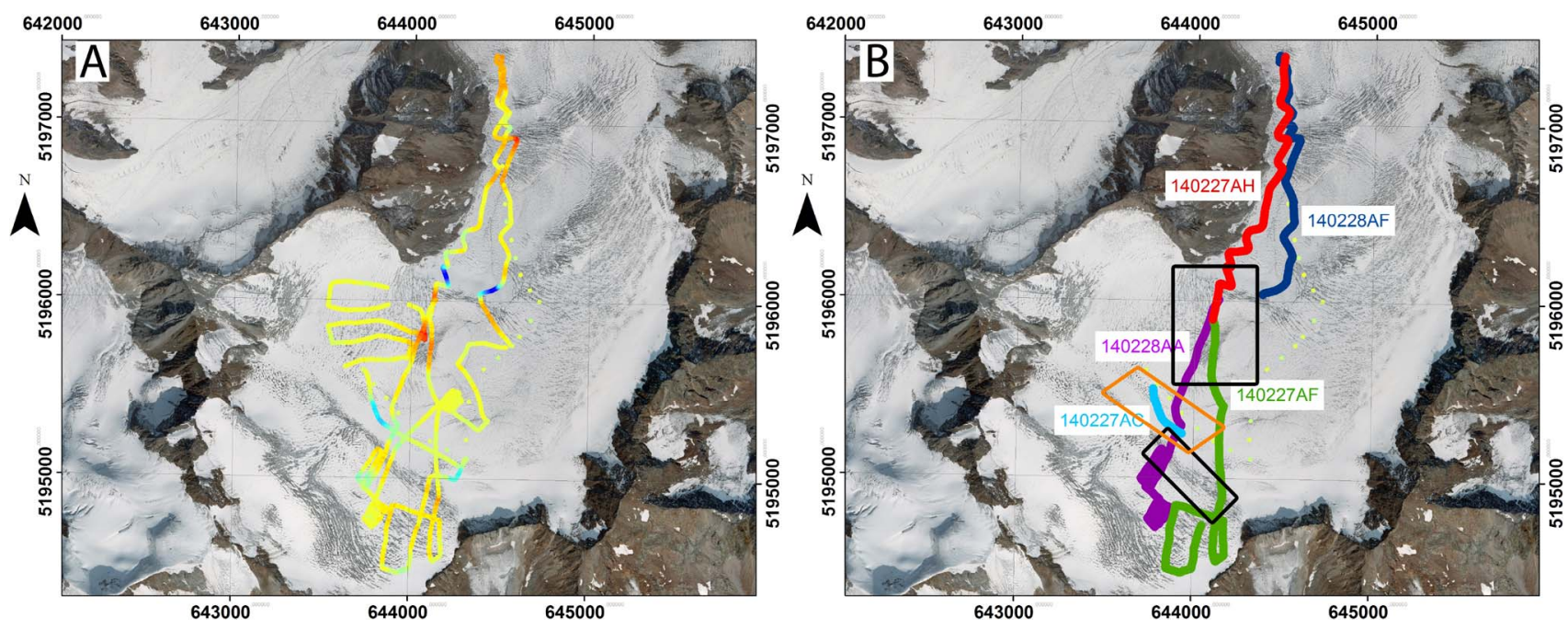

Fig. 6. GPR transects for February 27 and 28, 2014. (Left) Color coding of the GPR line represents observed snow depths from shallow (red: 0.6-1 m) to average (yellow: $1.5-2.5 \mathrm{~m}$ ) to very deep snow depths (blue: down to $7 \mathrm{~m}$ ). Single points with the same color coding represent manual snow probing locations. (Right) Color coding of the GPR line is associated with transect names. The black rectangles enclose the crevasse zones. The orange rectangle encloses an area with recent firn. Both figures are orthorectified and facing toward north. Coordinates are in UTM WGS 1984. The background image is an orthophoto from the Geodetical Information Service, Province of Tyrol.

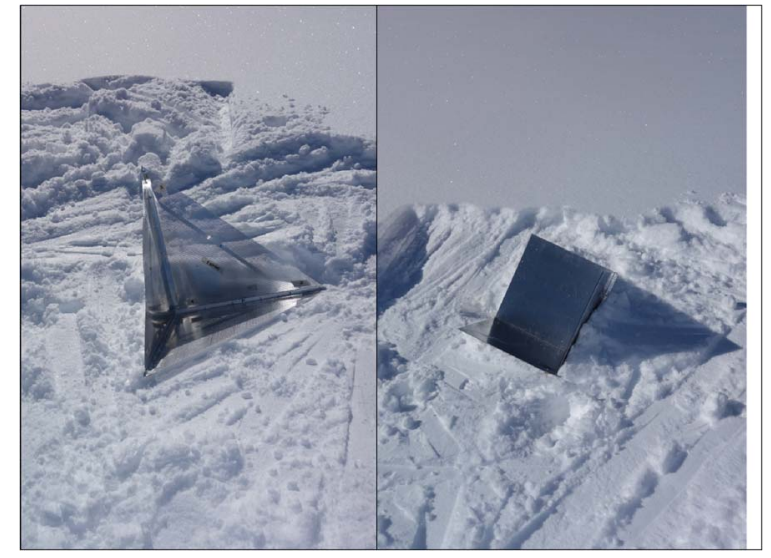

Fig. 7. (Left) Triangular trihedral reflector manufactured by ARESYS. (Right) Squared trihedral reflector manufactured by MetaSensing.

that it was acquired four years before AlpTomoSAR, was made a posteriori, after noting that it provided a sufficient accuracy to carry out a meaningful comparison between TomoSAR and GPR data. Voxel size (azimuth/ground range/height) is $d x=0.8 \mathrm{~m}, d y=3.2 \mathrm{~m}, d z=1 \mathrm{~m}$. TomoSAR cubes were afterward reprocessed, in order to correct the target's position by accounting for wave propagation velocity into the ice. This resulted in eight additional TomoSAR cubes, representing the average intensity at $15 \mathrm{~m} \times 15 \mathrm{~m}$ horizontal resolution. In the remainder, we will refer to these products as velocity-corrected TomoSAR cubes.

All TomoSAR products shown in the remainder are amplitude normalized, such that the integral over the elevation angle is unitary. This operation is quite often carried out in literature when presenting TomoSAR products, as it largely helps physical interpretation through the increase in image contrast [13]. Signal processing procedures required to generate TomoSAR cubes (SLC and velocity corrected) are briefly described in the remainder of this section. All SLC images and TomoSAR cubes were delivered to ESA as part of the outcomes of the AlpTomoSAR campaign, and these will be available to users through ESA's Earth Observation Principal Investigator (EOPI) portal.

\section{A. TomoSAR Cube Generation}

As discussed earlier, airborne tomographic data sets often need a preprocessing phase calibration step to correct phase residuals arising from subwavelength uncertainties about the position of the SAR antenna in each flight. In this paper, phase calibration was implemented through the approach in [31], which allows to accurately retrieve platform position directly from SAR data.

TomoSAR focusing was carried out by defocusing the SLC data using the trajectories provided by the navigational system and refocusing in the 3-D space using TDBP, based on the corrected flight trajectories from the previous phase calibration step. This approach has been preferred over performing a simple phase correction of SLC data, as it allows to correctly cope with large height-dependent coregistration offsets associated with large InSAR baselines and yaw angle deviations.

Vertical sections for both views at different polarizations $(\mathrm{HH}$ polarization) are shown in Fig. 8. In this case, the vertical coordinate represents absolute elevation in UTM coordinates, to show surface topography variation. Lidar surface elevation is represented by the white dashed line. Both sections reveal the presence of a scattering surface, whose position provides overall an excellent agreement with the Lidar DTM, despite the latter being four year older. Below this surface, a complex pattern of in-depth scatterers is observed as well. The apparent scattering depth is close to $100 \mathrm{~m}$, which corresponds to a physical penetration of about $50 \mathrm{~m}$ by considering ice propagation velocity.

1) Wave Propagation Velocity: If wave propagation velocity into the ice layer is not correctly accounted for in the focusing 

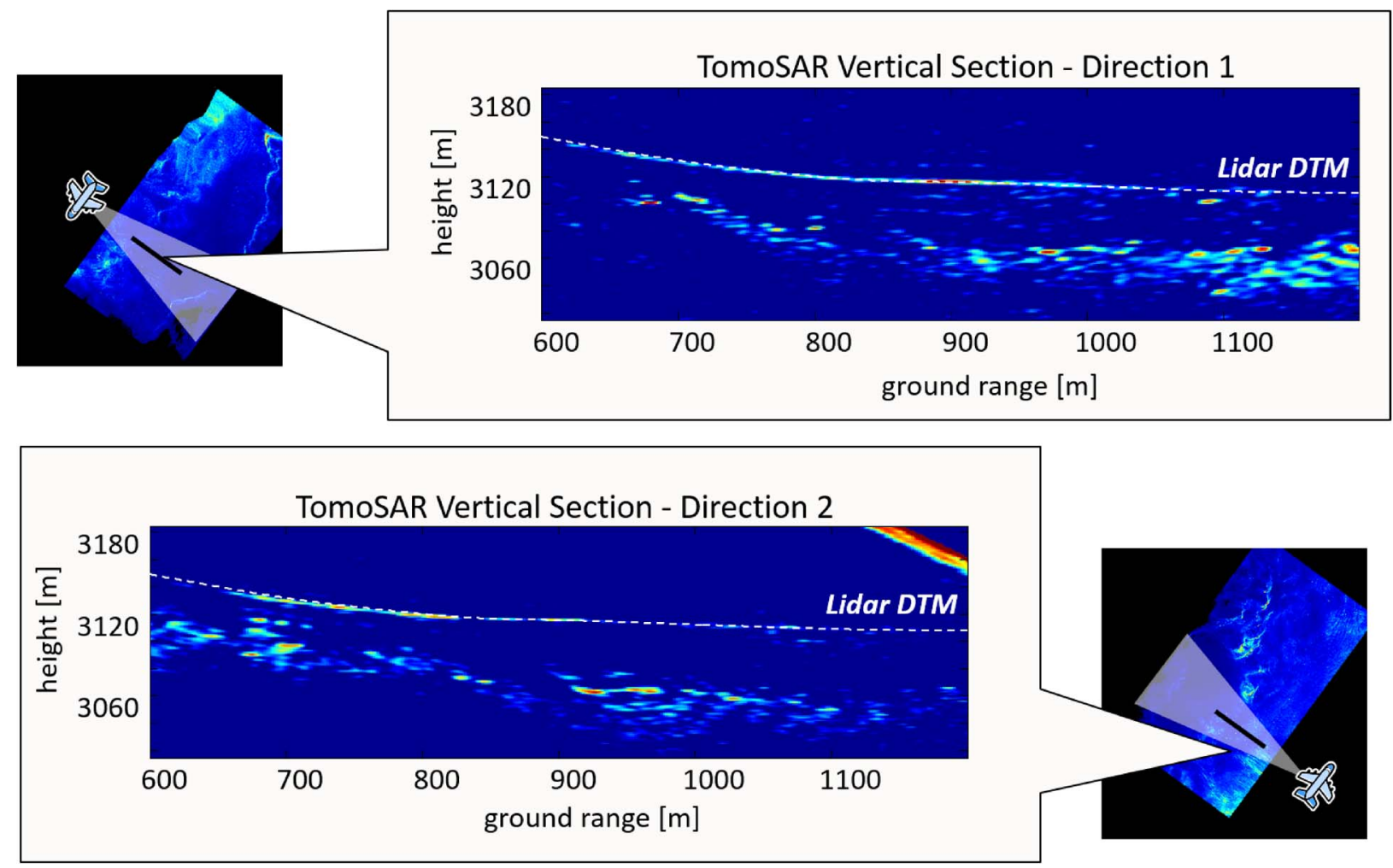

Fig. 8. TomoSAR vertical sections in the two opposite views (left and right columns). HH polarization. The white dashed line indicates Lidar surface height. Note that the two panels are not corrected for ice propagation velocity, which results in an apparent scattering depth of about $100 \mathrm{~m}$.

processor, the resulting images are likely to appear distorted, hindering the interpretation of the results. This problem can be treated by assuming Huygens' principle, after which the ice surface would act as a collection of secondary sources, to be propagated downward based on the knowledge of ice propagation velocity [38]-[40]. Under regularity conditions, that is by assuming local smoothness of the ice interface, the same problem can be rephrased by resorting to ray-tracing techniques [41]. This results in the sole assumption of a different propagation path than in free space, allowing to neglect further diffraction effects. The TDBP processor should be then modified in order to account for the effective propagation path from each sensor position to each subsurface target. A convenient approach to ray tracing in the presence of topographic variation of the ice surface is provided by Fermat's principle, which states that the effective propagation path is the one associated with the minimum travel time [41], as shown in Fig. 9. As discussed in [42], ray tracing should be embedded in the focusing processor before along-track focusing of each flight is performed, in order to avoid defocusing effects due to a nonperfect match of the phase histories of subsurface targets. In the generation of velocity-corrected TomoSAR cubes, however, an even more simple approach was assumed, by considering only the apparent target displacement in the ground range/height plane (see again Fig. 9). As shown in the Appendix, such a displacement can easily be on the order of several meters, or even tens of meters, which would invalidate a meaningful comparison to GPR data.

Velocity-corrected TomoSAR cubes were derived directly from multilooked TomoSAR cubes, assuming a simple, and indeed approximated, procedure. For each azimuth position,

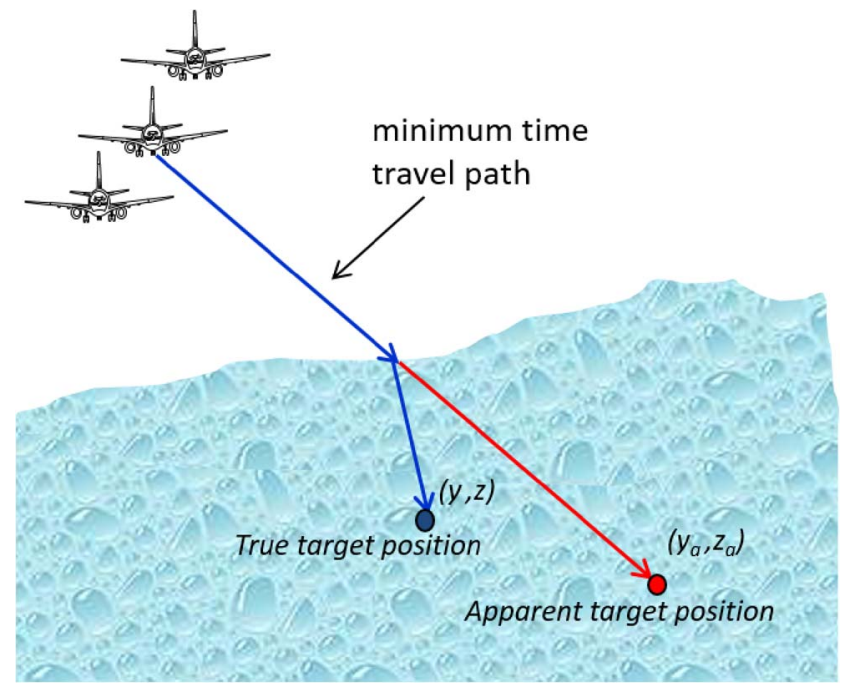

Fig. 9. True and apparent position of a subsurface target in the ground range/ height plane.

a 2-D mapping is established between the physical (i.e., true) and the apparent position of subsurface targets in the ground range/height plane, i.e., $\left(y_{a}(y, z), z_{a}(y, z)\right)$, where $(y, z)$ and $\left(y_{a}, z_{a}\right)$ represent physical and apparent target positions, respectively. Velocity-corrected TomoSAR cubes are then obtained by interpolating multilooked TomoSAR cubes, such that each subsurface voxel is brought to its physical position: $T_{v}(x, y, z)=T\left(x, y_{a}, z_{a}\right)$, where $T$ and $T_{v}$ indicate the 3-D TomoSAR cubes before and after the correction, respectively. 

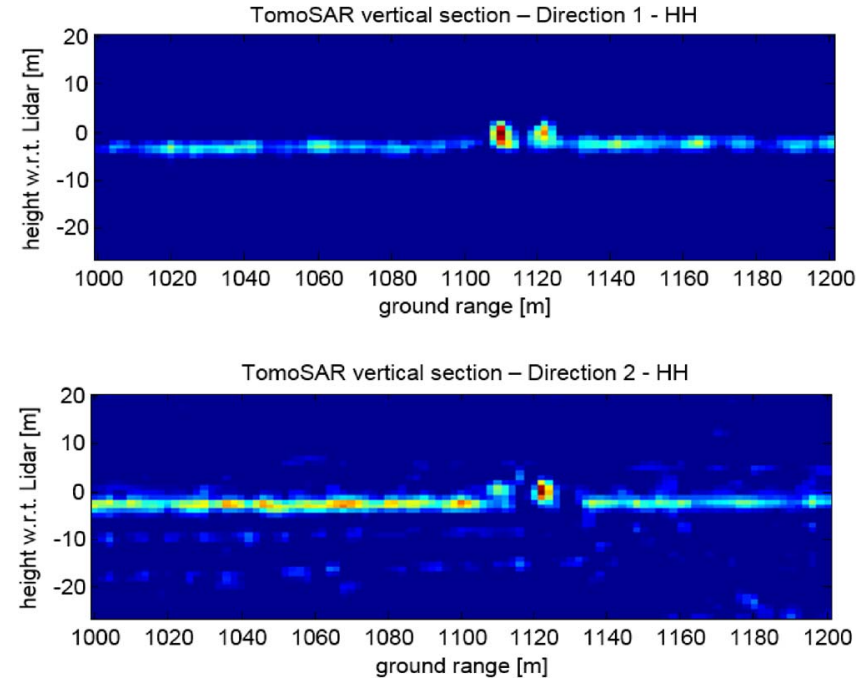

Fig. 10. TomoSAR vertical sections in correspondence of two trihedral reflectors in the two opposite views. The vertical coordinate represents the difference with respect to Lidar surface elevation.

The mapping between physical and apparent target positions was computed by ray tracing, searching exhaustively for the intersection point at the ice surface that yields the minimum travel time [41]. This computation was done by assuming a constant ice propagation velocity $v=0.168 \mathrm{~m} / \mathrm{ns}$ (consistently with GPR data processing) and considering the local topographic profile based on the Lidar DTM. It follows after the discussion earlier that this procedure is not optimal from the signal-processing point of view, as it may result in some residual defocusing effects for in-depth targets. However, this approach turned out to be accurate enough to allow for a direct comparison between TomoSAR and GPR, as shown in the remainder of this paper.

\section{RESUlTS AND DiscUSSION}

\section{A. Surface Scattering}

Fig. 10 shows two TomoSAR vertical sections corresponding to one pair of corner reflectors, as imaged in the two opposite views. In both panels, the vertical coordinate represents the difference with respect to Lidar surface elevation. The two corners appear in both views as bright points, which are located approximately 2-3 $\mathrm{m}$ above a scattering surface, consistently with in situ measurements of snowpack depth. In each of the two views, the brightest corner is the one facing the radar. All corners were deployed directly on the snowpack surface. Accordingly, the observed displacement with respect to surface scattering implies that the latter corresponds to the snow/ice interface, whereas the snow volume, featuring low density, does not appear to contribute to the signal.

\section{B. Direct Comparison to 200-MHz GPR Data}

For direct comparison of GPR-recorded signal responses with TomoSAR signatures, we resampled velocity-corrected TomoSAR cubes at the locations of the GPR transects. Promi- nent glacier features, with a very pronounced and distinguishable signal response in GPR data, are described as follows:

- discontinuities in crevasse zones;

- bedrock reflection;

- transitions to inhomogeneous layers;

- annual layering in firn regions.

Different transects are discussed in the following. For the sake of clearness, we point out that the vertical axis in GPR transects is associated with depth below the snow surface in February 2014, whereas in TomoSAR transects it represents the difference with respect to surface elevation obtained by the Lidar survey four years before. Accordingly, the vertical axes in GPR and TomoSAR transects might show a slight relative offset, depending on snow accumulation and/or topographic changes between the two dates.

The position of the analyzed transects is shown in the right panel in Fig. 6.

1) Crevasses: The GPR radargram and the TomoSAR profiles corresponding to transect $140227 \mathrm{AF}$ are shown in Fig. 11. Vertical stripes are observed ranging from the ice surface to about $20 \mathrm{~m}$ in depth with increased amplitudes, which are typical features indicating crevasses. Such vertical striping in pulsed GPR data can be explained by discontinuity (gaps) in the underlying ice layer. In particular, while approaching and departing crevasses, diffraction hyperbolas are generated at the transition air/ice within the crevasse. Since the data in all radargrams are migrated, hyperbolas are collapsed to single points of larger amplitude. Within crevasse zones, both GPR and TomoSAR data are influenced by the verticality of the air/ice interface. The dielectric permittivity changes in crevasse areas cause strong signal responses at the surface and, in consequence, reduce the transmission of electromagnetic energy into deeper parts of the glacier. Hence, neither for GPR data nor for TomoSAR, we can clearly identify the ice/bedrock interface. It appears that GPR data can provide a slightly better resolution of the ice thickness in such crevassed areas. This can be explained by the GPR nadir-looking acquisition geometry, which shows signal responses in between crevasses.

2) Bedrock Reflection and Transition to Inhomogeneous Layers: The GPR radargram corresponding to transect $140227 \mathrm{AH}$ is shown in the top panel in Fig. 12. The bedrock underneath homogeneous ice appears as very sharp reflection due to strong gradients in dielectric properties at the transition icerock. A continuous reflector from $200 \mathrm{~m}$ in distance to at least $1500 \mathrm{~m}$ is visible, which rises up to the snow layer at about $500 \mathrm{~m}$ in distance. Regions in a distance of 1300-1380 $\mathrm{m}$ and from $1500 \mathrm{~m}$ onward are dominated by artifacts generated by some transmitter in the same frequency range as the GPR. These distance ranges are in close proximity to the Pitztal skiing area, where interferences are expected. A very similar bedrock signature is observed in the corresponding TomoSAR transects, as shown in the middle and bottom panels in Fig. 12. The bedrock appears at the same depth as in the GPR transect, and even for areas where GPR data are masked by some external transmitter, a clear signature of the bedrock is detected. The maximum depth for this transect is observed to be about $45 \mathrm{~m}$, at a distance of about $400 \mathrm{~m}$. 

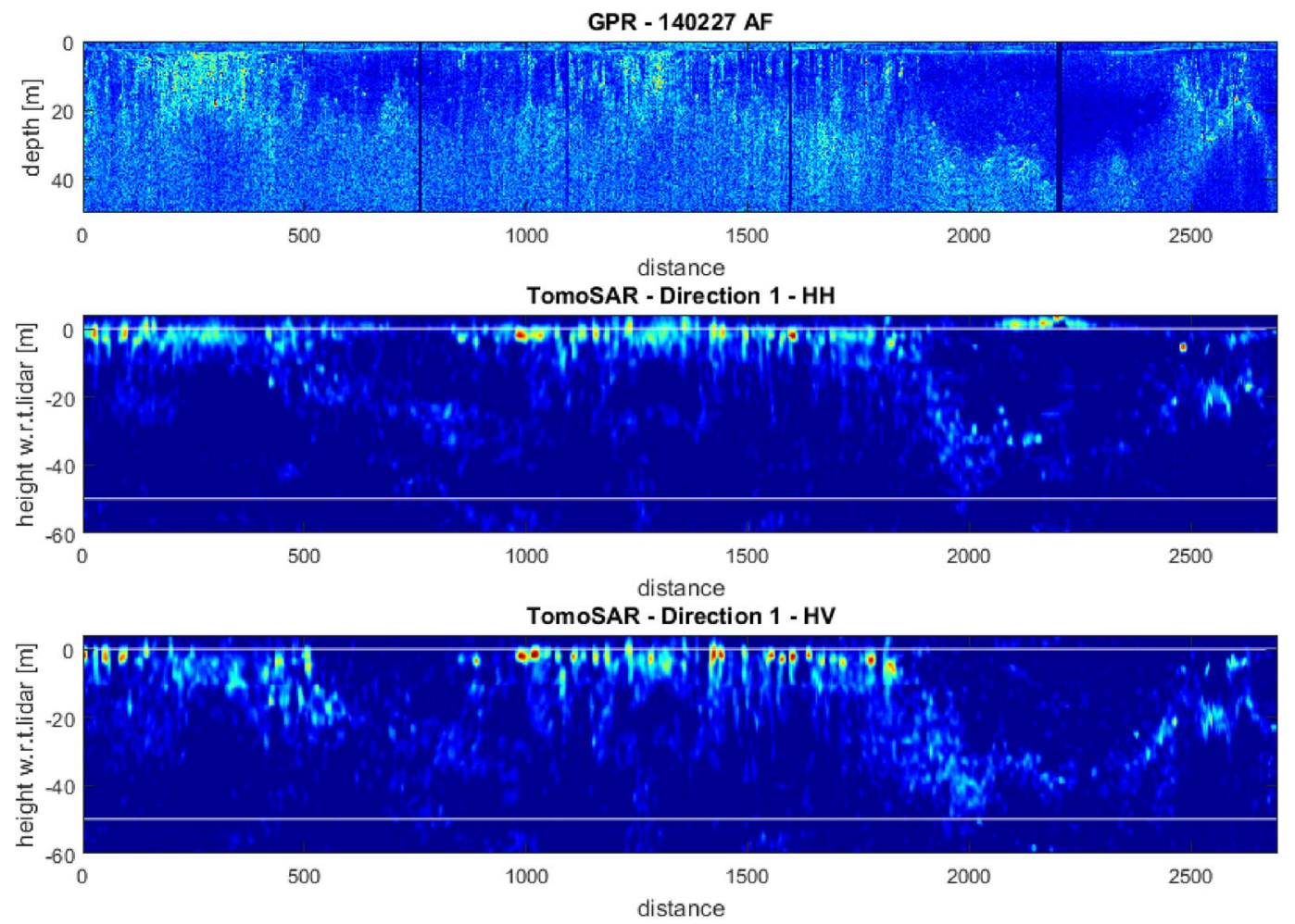

Fig. 11. (Top) 200-MHz GPR transect. (Middle) HH and (bottom) HV TomoSAR transects as obtained by interpolating the TomoSAR cube at GPR coordinates.
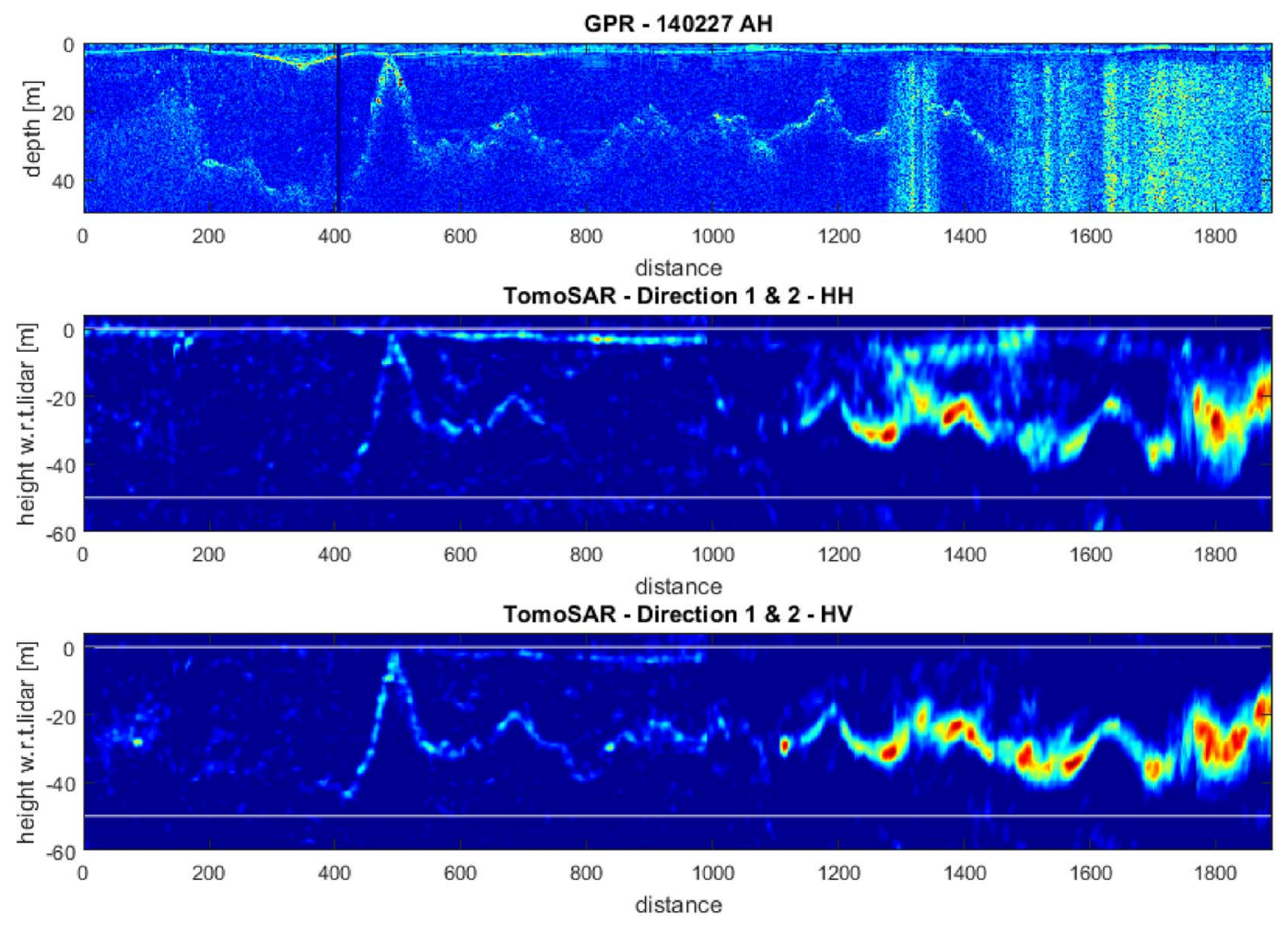

Fig. 12. (Top) 200-MHz GPR transect. (Middle) HH and (bottom) HV TomoSAR transects as obtained by interpolating the TomoSAR cube at GPR coordinates. These TomoSAR transects are obtained as a mosaic between directions 1 and 2. The transects from direction 1 are displayed for distances from 0 to $990 \mathrm{~m}$. The transects from direction 2 are displayed for distances from 990 to $1890 \mathrm{~m}$.

Transect 140228 AA, on the other side, is mostly characterized by internal scattering for the recorded GPR traces, as shown in the top panel in Fig. 13. Such scattering evokes through lateral inhomogeneities. The scatterers at a distance from 0 to $400 \mathrm{~m}$, from 850 to $1000 \mathrm{~m}$, and from 1250 to $1600 \mathrm{~m}$ are caused by crevasses, which were crossed at such distances (see Fig. 6 for comparison). The grainy region within the lower part of the radar transect is possibly due to some 


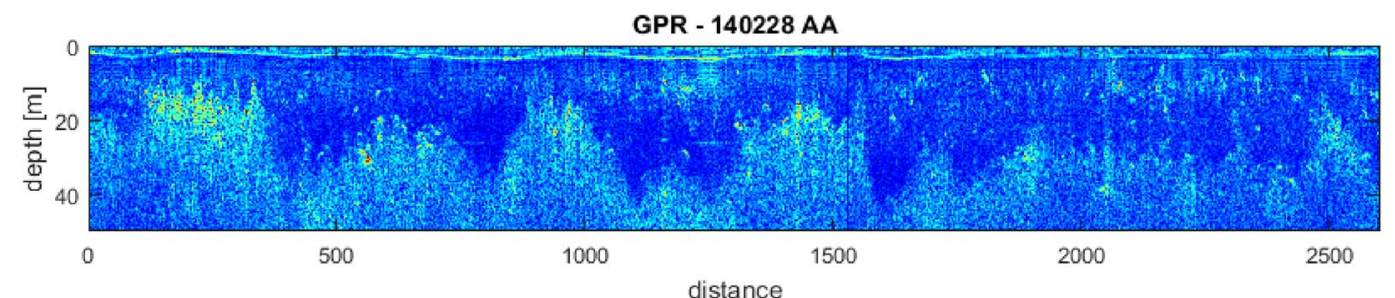

TomoSAR - Direction 1 - HH
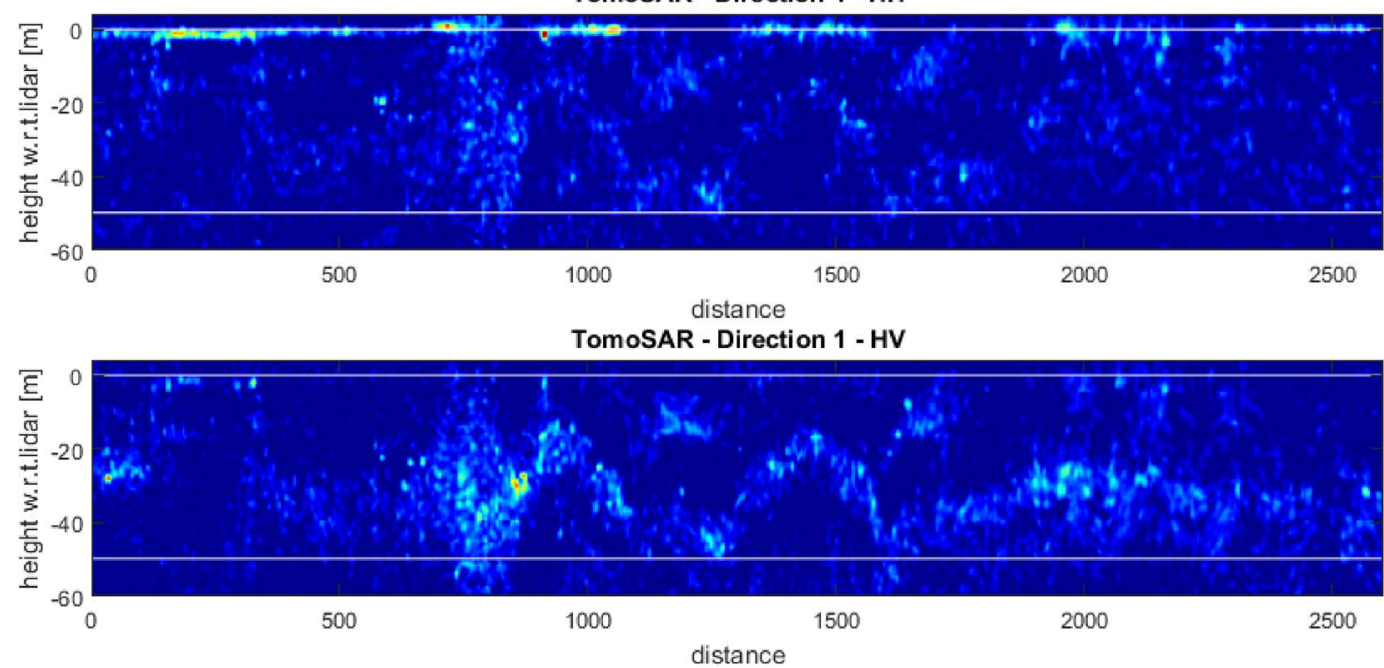

Fig. 13. (Top) 200-MHz GPR transect. (Middle) HH and (bottom) HV TomoSAR transects as obtained by interpolating the TomoSAR cube at GPR coordinates.
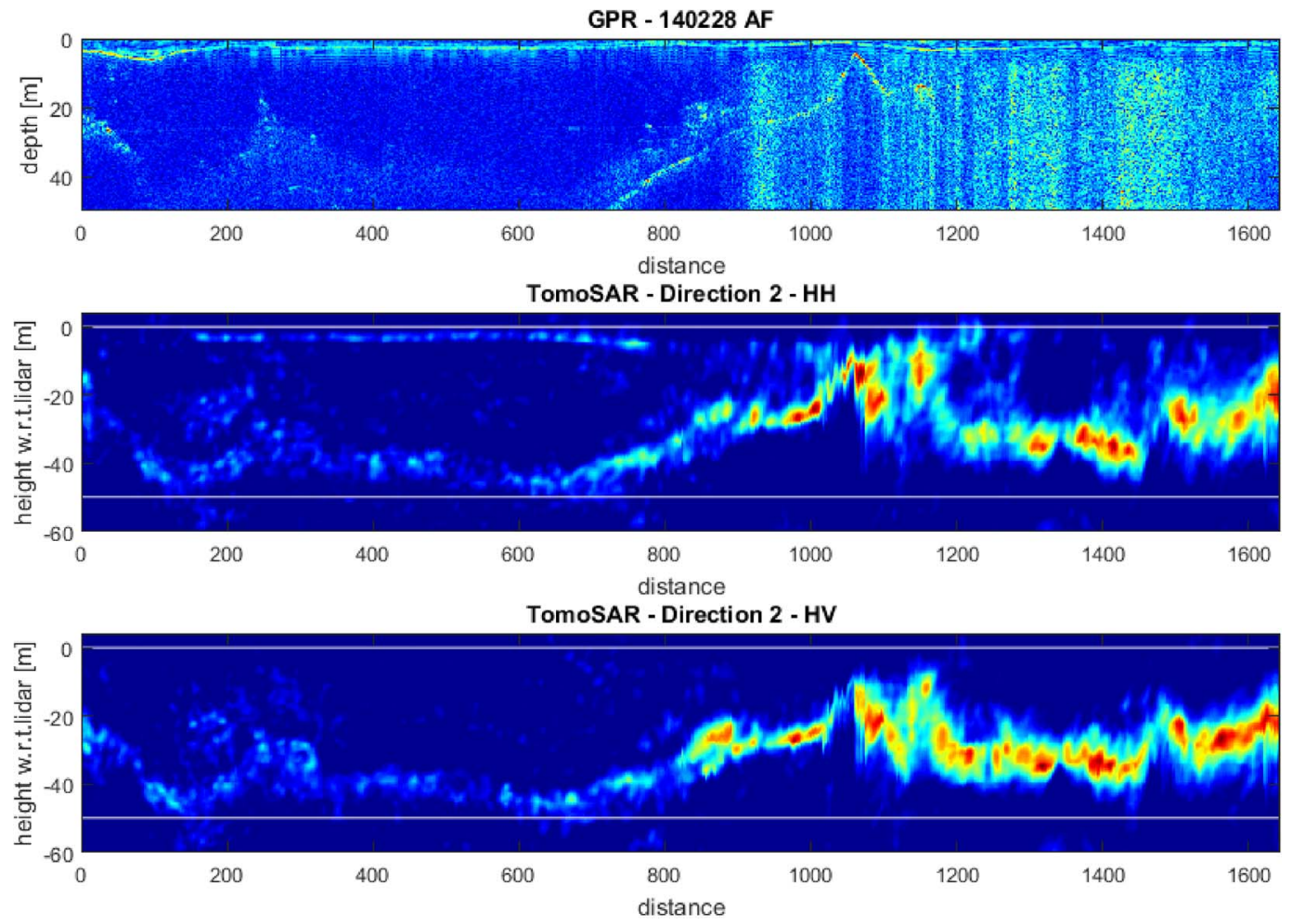

Fig. 14. (Top) 200-MHz GPR transect. (Middle) HH and (bottom) HV TomoSAR transects as obtained by interpolating the TomoSAR cube at GPR coordinates.

old firn to ice transitions (in the 600-MHz GPR data, we still detect some old firn stratigraphy). The transition from firn to ice, however, is more gradual than sharp, and in consequence, no distinct reflector appears. The crevasse influences within this region are detectable in the TomoSAR profiles as well, as shown in the middle and bottom panels in Fig. 13. However, the TomoSAR signal is observed to rapidly decay with depth as compared to the GPR radargram, which indicates that such an inhomogeneous layer transition does not allow propagation of L-band waves down to the bedrock. 

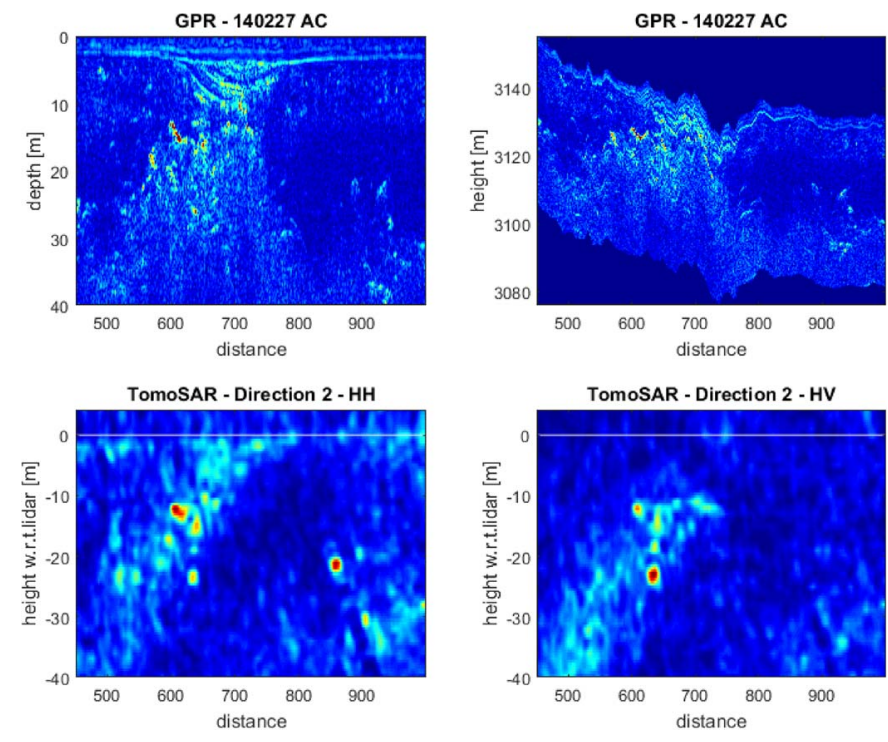

Fig. 15. (Top) 200-MHz GPR transect. The vertical axis in the top right panel corresponds to absolute height over the sea level. (Bottom) TomoSAR transects at $\mathrm{HH}$ and $\mathrm{HV}$ as obtained by interpolating the TomoSAR cube at GPR coordinates.

The GPR radargram corresponding to transect 140228 AF (top panel in Fig. 14) displays two different situations. The bedrock reflection below the ice surface is clearly observed in the central part of the transect, at a distance from about 750 to $1100 \mathrm{~m}$ (at distances beyond $1200 \mathrm{~m}$, the GPR signal is dominated by radio interferences). At a distance from 0 to $700 \mathrm{~m}$, the GPR radargram appears instead grainy, which indicates transition to an inhomogeneous layer, similar to transect 140228 AA. The corresponding TomoSAR profiles are shown in the middle and bottom panels in Fig. 14. In this case, the bedrock reflection is detected down to a depth of some $35 \mathrm{~m}$, at a distance of about $850 \mathrm{~m}$. In the interval of distances from 0 to $850 \mathrm{~m}$, the tomograms show scattering events that correspond to the upper part of the grainy region observed in the GPR radargram. As in the case of transect $140228 \mathrm{AA}$, this indicates that the presence of inhomogeneous layers may hinder wave penetration at L-band.

3) Firn: Firn regions with a distinct stratigraphy are very rare for the Mittelbergferner, at least for the glacier parts, which were covered by the GPR transects. An area with annual firn layers was found within a surface depression below the uppermost plateau of the glacier (see orange rectangle in Fig. 6). The corresponding GPR radargram is shown in the top left panel in Fig. 15. Firn layers are observable in the upper part of this figure, at a distance from 600 to $750 \mathrm{~m}$ and a depth from 4 to $10 \mathrm{~m}$. The same radargram is also displayed in the top right panel of the same figure, after being corrected for recorded topography. Here, absolute elevation is plotted on the vertical instead of depth from the surface, to support interpretation of local phenomena, such as, e.g., water tables. The firn stratigraphy is observed to be closely related to the topography. Within the topography depression, we can identify more annual summer surface horizons and thicker firn layers. Even the recent snowpack is significantly larger for the depression region.
The corresponding TomoSAR profiles are shown in the bottom panels in Fig. 15. Firn stratigraphy cannot be directly identified in TomoSAR data. However, we observed that the area corresponding to firn layering appears as homogeneous scattering at $\mathrm{HH}$, whereas it disappears at $\mathrm{HV}$, consistently with the physics of surface scattering.

Another relevant feature is the presence of dominant reflectors below the firn stratigraphy. Such reflectors are observed in Fig. 15, at a distance from 550 to $700 \mathrm{~m}$ and a depth from 10 to about $25 \mathrm{~m}$, both in the GPR radargram (top right panel) and in the corresponding TomoSAR profiles at both polarizations (bottom panels). Such dominant reflectors provide an indication for heterogeneous small-scale reflectors within the firn regions, which are most likely associated with the presence of pockets of liquid water. It is also worth noting that wave penetration in this area is observed to be hindered by the presence of firn. However, it is not straightforward to generalize this conclusion since firn areas are very rare on this site, and the one here considered is also characterized by a complex topography.

\section{Three-Dimensional Polarimetric Imaging}

The variation of the polarimetric intensities with depth is analyzed by considering TomoSAR horizontal sections corresponding to different depths with respect to the Lidar surface. Results are visualized in Fig. 16, where each section is color coded, such that $\mathrm{HH}=$ red, $\mathrm{HV}=$ green, VV = blue. For the sake of clearness, we recall here that all TomoSAR products shown in this paper are normalized, such that the integral over the elevation angle is unitary. It follows that the information about the absolute power is not displayed.

The section at the surface level (top panel) is observed to be mostly violet, indicating that the (normalized) contributions of $\mathrm{HH}$ and $\mathrm{VV}$ at the surface level are balanced and largely predominating HV. Conversely, TomoSAR sections at 25 and $50 \mathrm{~m}$ below the surface (middle and bottom panels) are characterized by many green areas, indicating relevant in-depth cross-polarization contributions. Based on these observations, it is immediate to conclude that scattering from the ice surface contributes to the signal in copolarized channels, whereas it is largely absent in cross-polarization. Such scattering features are consistent with the Bragg scattering model [43], typical for slightly rough surfaces. Conversely, contributions from indepth scatterers are observed to contribute to all polarizations.

\section{Conclusion}

The AlpTomoSAR experiment has been conceived to investigate the potential of TomoSAR for mapping 3-D internal structures of glaciers and ice sheets. The scientific rationale built mainly on previous results about tomographic imaging of forested areas, which is widely investigated in the frame of SAR remote sensing of forests. The campaign has encompassed coincident in situ measurements of physical snow properties and GPR tracks, as well as SAR surveys, gathered in about two weeks from the end of February to the beginning of March 2014. Field works have also included deployment, maintenance, and dismantlement of eight corner reflectors. SAR data were acquired by repeatedly flying over the Mittelbergferner 


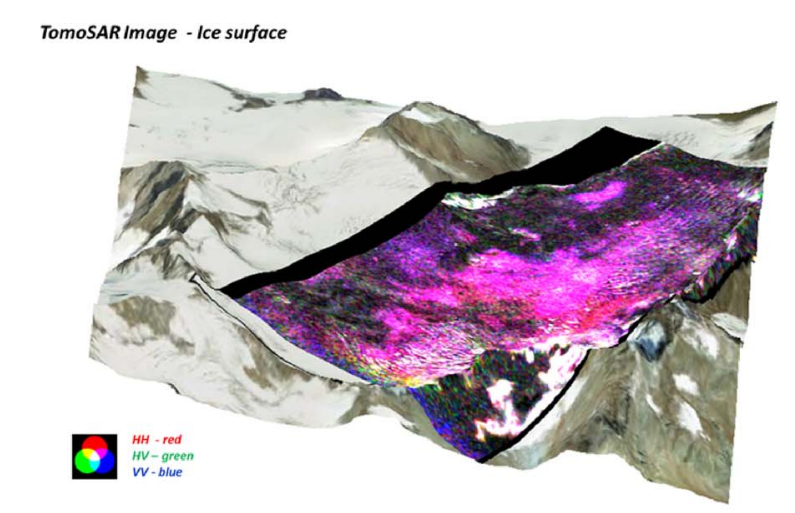

TomoSAR Image - $25 \mathrm{~m}$ below the ice surface

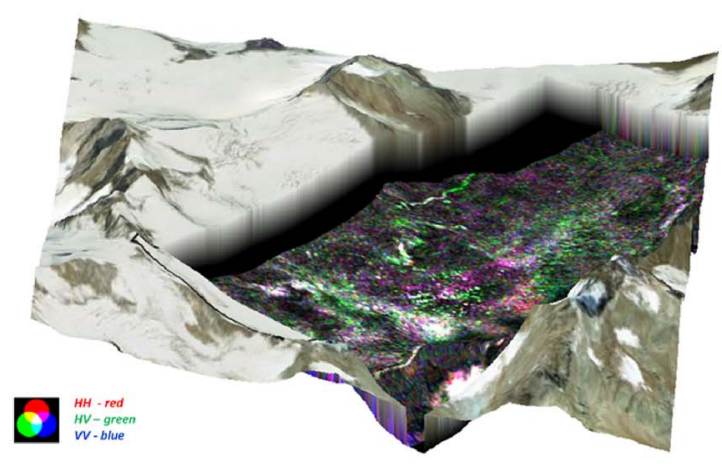

TomoSAR Image - $50 \mathrm{~m}$ below the Ice surface

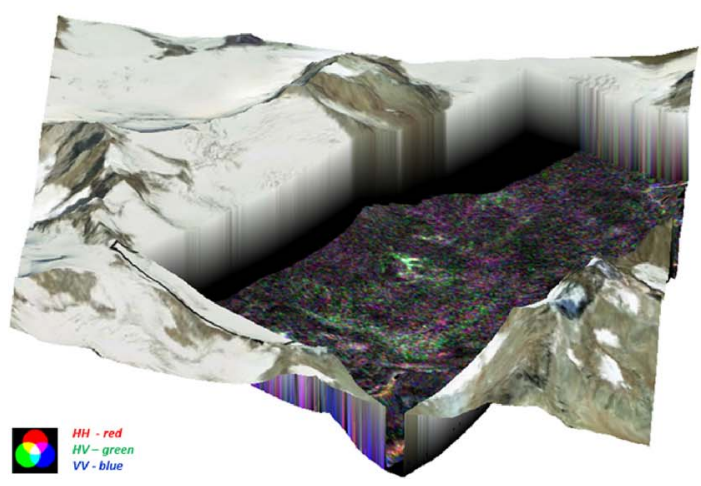

Fig. 16. Normalized polarimetric intensities as a function of depth.

along an oval-like racetrack configuration, to illuminate the scene from two opposite viewpoints. Subsequently, all data were back projected in the 3-D space to generate 3-D reflectivity maps of the Mittelbergferner glacier, which are referred throughout this paper as TomoSAR cubes. A further processing step was implemented to correct for the change of the propagation velocity in the ice layer.

The analysis of TomoSAR cubes immediately reveals the complexity of the glacier subsurface scattering. Most areas are characterized by surface scattering in proximity of the Lidar surface, plus a complex pattern of in-depth volumetric scattering beneath. In some areas, a significant backscatter signal is observed in the top 10-20 m, which is related to firn bodies or crevasses. In other areas, where the volume consists of compact ice, a gap on the order of $10-20 \mathrm{~m}$ is observed between surface and in-depth scattering. These results show that modeling the scattering from ice layers, in terms of an exponential decay due to uniform wave extinction, is definitely insufficient for characterizing glaciers. The large availability of in situ information allowed to further analyze TomoSAR cubes and associate the observed features with a physical interpretation. Corner reflectors, which were deployed on the snow surface, were observed in TomoSAR cubes, floating about 2-3 $\mathrm{m}$ above a surface scattering. This observation implies that the observed surface in TomoSAR cubes corresponds to the snow/ice interface, whereas the volume of the comparatively fine-grained winter snowpack does not appear to contribute to the signal. This result is also confirmed by field measurements of snowpack depth. Various subsurface features observed in GPR transects at $200 \mathrm{MHz}$ clearly showed up in TomoSAR sections as well, particularly firn bodies, crevasses, layer transitions, and bedrock reflection down to $50 \mathrm{~m}$ below the ice surface. Accordingly, the AlpTomoSAR experiment has provided evidence that, for a temperate glacier, L-band waves can penetrate down to few tens of meters, and that TomoSAR can successfully be employed to derive information similar to lowfrequency GPR surveys.

Further efforts should be dedicated to the development of retrieval methods for ice parameters. For example, tomographic data have been shown to provide sensitivity to wave propagation velocity in the ice volume. In this paper, we corrected the data using a constant velocity, which was sufficient to compare TomoSAR to GPR. Future work may include methods to infer the 3-D distribution of wave propagation velocity directly from SAR data.

\section{APPENDIX}

\section{Apparent Target Displacement With DePTh}

In this appendix, we will derive a simple model to describe the displacement of a subsurface target when focused, assuming propagation in air. For the sake of simplicity, we consider a single interface, which we here assume to correspond to the ice surface, whose topography is flat, as shown in Fig. 17. A generic target is localized in the height/ground range plane based on the following: 1) the delay undergone by the transmitted signal as it is backscattered by the target to the receiving array, which is converted into a distance based on the knowledge of propagation velocity; 2) the direction of the wave impinging on the receiving array, which is represented by the multibaseline aperture, that provides the incidence angle for that target.

Consider now a certain pair of delay and angle values $(\tau, \theta)$, and let the delay be decomposed into the components relative to propagation in air and in the ice layer, i.e., $\tau=\tau_{\text {air }}+\tau_{i}$. The corresponding target position assuming propagation in air is then

$$
\begin{aligned}
& y_{a}=y_{\mathrm{int}}+\frac{c \tau_{i}}{2} \sin \theta \\
& z_{a}=z_{\mathrm{int}}-\frac{c \tau_{i}}{2} \cos \theta
\end{aligned}
$$




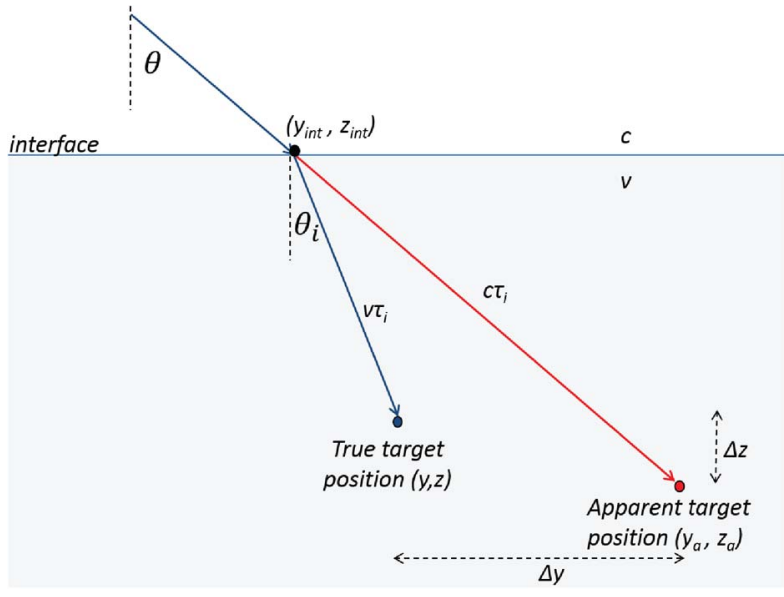

Fig. 17. True and apparent positions of a subsurface target.

where $\left(y_{\mathrm{int}}, z_{\mathrm{int}}\right)$ are the coordinates at which the interface is crossed by the ray to the target, and $c$ is the propagation velocity in air. In the case of wave propagation into the ice layer, (3) has to be modified in order to account for ice propagation velocity and the consequent change of incidence angle, resulting in

$$
\begin{aligned}
& y=y_{\text {int }}+\frac{v \tau_{i}}{2} \sin \theta_{i} \\
& z=z_{\text {int }}-\frac{v \tau_{i}}{2} \cos \theta_{i}
\end{aligned}
$$

where $v$ is the ice propagation velocity, and $\theta_{i}$ is the incidence angle into the ice layer, which follows after Snell's law: $c \cdot \sin \theta_{i}=v \cdot \sin \theta$. The apparent target displacement is then obtained by taking the difference between (3) and (4), as follows:

$$
\begin{aligned}
& \triangle y=\frac{\tau_{i}}{2}\left(c \cdot \sin \theta-v \cdot \sin \theta_{i}\right) \\
& \triangle z=\frac{\tau_{i}}{2}\left(v \cdot \cos \theta_{i}-c \cdot \cos \theta\right) .
\end{aligned}
$$

The displacement can be easily related to target depth below the interface $(d)$ through the equation $d=\left(v \tau_{i} / 2\right) \cos \theta_{i}$, yielding

$$
\begin{aligned}
& \triangle y=\frac{d}{v \cos \theta_{i}}\left(c \cdot \sin \theta-v \cdot \sin \theta_{i}\right) \\
& \triangle z=\frac{d}{v \cos \theta_{i}}\left(v \cdot \cos \theta_{i}-c \cdot \cos \theta\right) .
\end{aligned}
$$

As an example, assuming that ice velocity is $v=0.168 \mathrm{~m} / \mathrm{ns}$ and at an incidence angle around $45^{\circ}$, one gets $\triangle y \simeq 0.94 \cdot d$, meaning that the horizontal displacement is as large as the target depth.

\section{ACKNOWLEDGMENT}

The authors would like to thank the whole AlpTomoSAR team, for the precious collaboration; A. Coccia (MetaSensing), who was in charge of the airborne campaign; Dr. M. Davidson (ESA) and Dr. D. Schuettemeyer (ESA), for their support and for most valuable discussions about the implementation of this experiment; Prof. F. Rocca (Politecnico di Milano), for insights and most valuable suggestions on many aspects of this work; and the anonymous reviewers, for their careful reading of our manuscript and their accurate comments, which helped us improve the quality of this paper.

\section{REFERENCES}

[1] E. Weber Hoen and H. Zebker, "Penetration depths inferred from interferometric volume decorrelation observed over the Greenland ice sheet," IEEE Trans. Geosci. Remote Sens., vol. 38, no. 6, pp. 2571-2583, Nov. 2000.

[2] J. Sharma, I. Hajnsek, K. Papathanassiou, and A. Moreira, "Polarimetric decomposition over glacier ice using long-wavelength airborne PolSAR," IEEE Trans. Geosci. Remote Sens., vol. 49, no. 1, pp. 519-535, Jan. 2011.

[3] J. Sharma, I. Hajnsek, K. Papathanassiou, and A. Moreira, "Estimation of glacier ice extinction using long-wavelength airborne Pol-InSAR," IEEE Trans. Geosci. Remote Sens., vol. 51, no. 6, pp. 3715-3732, Jun. 2013.

[4] F. Banda, J. Dall, and S. Tebaldini, "Single and multipolarimetric P-band SAR tomography of subsurface ice structure," IEEE Trans. Geosci. Remote Sens., vol. 54, no. 5, pp. 2832-2845, May 2016.

[5] A. Moreira et al., "Tandem-L: A highly innovative bistatic SAR mission for global observation of dynamic processes on the Earth's surface," IEEE Geosci. Remote Sens. Mag., vol. 3, no. 2, pp. 8-23, Jun. 2015.

[6] P. Prats, R. Scheiber, A. Reigber, C. Andres, and R. Horn, "Estimation of the surface velocity field of the Aletsch glacier using multibaseline airborne SAR interferometry," IEEE Trans. Geosci. Remote Sens. vol. 47, no. 2, pp. 419-430, Feb. 2009.

[7] G. Parrella, I. Hajnsek, and K. Papathanassiou, "Polarimetric decomposition of L-band PolSAR backscattering over the Austfonna ice cap," IEEE Trans. Geosci. Remote Sens., vol. 54, no. 3, pp. 1267-1281, Mar. 2016.

[8] A. Reigber and A. Moreira, "First demonstration of airborne SAR tomography using multibaseline L-band data," IEEE Trans. Geosci. Remote Sens., vol. 38, no. 5, pp. 2142-2152, Sep. 2000.

[9] M. Mariotti d'Alessandro and S. Tebaldini, "Phenomenology of P-band scattering from a tropical forest through three-dimensional SAR tomography," IEEE Geosci. Remote Sens. Lett., vol. 9, no. 3, pp. 442-446, May 2012.

[10] Y. Huang, L. Ferro-Famil, and C. Lardeux, "Polarimetric SAR tomography of tropical forests at P-band," in Proc. IEEE IGARSS, Jul. 2011, pp. 1373-1376.

[11] D. Ho Tong Minh et al., "Relating P-band synthetic aperture radar tomography to tropical forest biomass," IEEE Trans. Geosci. Remote Sens., vol. 52, no. 2, pp. 967-979, Feb. 2014.

[12] O. Frey and E. Meier, "Analyzing tomographic SAR data of a forest with respect to frequency, polarization, and focusing technique," IEEE Trans. Geosci. Remote Sens., vol. 49, no. 10, pp. 3648-3659, Oct. 2011.

[13] S. Tebaldini and F. Rocca, "Multibaseline polarimetric SAR tomography of a boreal forest at P- and L-bands," IEEE Trans. Geosci. Remote Sens. vol. 50, no. 1, pp. 232-246, Jan. 2012.

[14] O. Ponce, P. Prats, R. Scheiber, A. Reigber, I. Hajnsek, and A. Moreira, "Polarimetric 3-D imaging with airborne holographic SAR tomography over glaciers," in Proc. IEEE IGARSS, Jul. 2015, pp. 5280-5283.

[15] S. Tebaldini, T. Nagler, H. Rott, and A. Heilig, "L-band 3D imaging of an Alpine glacier: Results from the AlpTomoSAR campaign," in Proc. IEEE IGARSS, Jul. 2015, pp. 5212-5215.

[16] "SAOCOM Companion Satellite Science Report," ESA, Noordwijk, The Netherlands, 2015.

[17] P. Pasquali et al., "A 3-D SAR experiment with EMSL data," in Proc. IGARSS, Quantitative Remote Sens. Sci. Appl., Jul. 1995, vol. 1, pp. 784-786.

[18] X. X. Zhu and R. Bamler, "Very high resolution spaceborne SAR tomography in urban environment," IEEE Trans. Geosci. Remote Sens., vol. 48, no. 12, pp. 4296-4308, Dec. 2010.

[19] G. Fornaro, F. Lombardini, and F. Serafino, "Three-dimensional multipass SAR focusing: Experiments with long-term spaceborne data," IEEE Trans. Geosci. Remote Sens., vol. 43, no. 4, pp. 702-714, Apr. 2005.

[20] L. Ferro-Famil, S. Tebaldini, M. Davy, and F. Boute, "3D SAR imaging of the snowpack in presence of propagation velocity changes: Results from the AlpSAR campaign," in Proc. IEEE IGARSS, Jul. 2014 pp. 3370-3373.

[21] S. Tebaldini, "Single and multipolarimetric SAR tomography of forested areas: A parametric approach," IEEE Trans. Geosci. Remote Sens. vol. 48, no. 5, pp. 2375-2387, May 2010.

[22] F. Lombardini and A. Reigber, "Adaptive spectral estimation for multibaseline SAR tomography with airborne L-band data," in Proc. IEEE IGARSS, Jul. 2003, vol. 3, pp. 2014-2016. 
[23] F. Lombardini and M. Pardini, "3-D SAR tomography: The multibaseline sector interpolation approach," IEEE Geosci. Remote Sens. Lett., vol. 5, no. 4, pp. 630-634, Oct. 2008.

[24] F. Gini, F. Lombardini, and M. Montanari, "Layover solution in multibaseline SAR interferometry," IEEE Trans. Aeros. Electron. Syst., vol. 38, no. 4, pp. 1344-1356, Oct. 2002.

[25] E. Aguilera, M. Nannini, and A. Reigber, "A data-adaptive compressed sensing approach to polarimetric SAR tomography of forested areas," IEEE Geosci. Remote Sens. Lett., vol. 10, no. 3, pp. 543-547, May 2013.

[26] O. Frey and E. Meier, "Tomographic focusing by combining time-domain back-projection and multi-looking based focusing techniques," in Proc. 7th EUSAR, Jun. 2008, pp. 1-3.

[27] O. Frey, C. Magnard, M. Ruegg, and E. Meier, "Focusing of airborne synthetic aperture radar data from highly nonlinear flight tracks," IEEE Trans. Geosci. Remote Sens., vol. 47, no. 6, pp. 1844-1858, Jun. 2009.

[28] M. Nannini and R. Scheiber, "Height dependent motion compensation and coregistration for airborne SAR tomography," in Proc. IEEE IGARSS, Jul. 2007, pp. 5041-5044.

[29] A. Reigber, P. Prats, and J. Mallorqui, "Refined estimation of time-varying baseline errors in airborne SAR interferometry," IEEE Geosci. Remote Sens. Lett., vol. 3, no. 1, pp. 145-149, Jan. 2006.

[30] S. Tebaldini and A. Guarnieri, "On the role of phase stability in SAR multibaseline applications," IEEE Trans. Geosci. Remote Sens., vol. 48, no. 7, pp. 2953-2966, Jul. 2010.

[31] S. Tebaldini, F. Rocca, M. Mariotti d'Alessandro, and L. Ferro-Famil, "Phase calibration of airborne tomographic SAR data via phase center double localization," IEEE Trans. Geosci. Remote Sens., vol. 54, no. 3, pp. 1775-1792, Mar. 2015.

[32] H. Rott et al., "Ku- and X-band backscatter analysis and SWE retrieval for Alpine snow," in Proc. IEEE IGARSS, Jul. 2014, pp. 2407-2410.

[33] H. Rott, T. Nagler, E. Ripper, K. Voglmeier, R. Prinz, and R. Fromm, "Retrieval of snow mass using Ku- and X-band SAR data," in Proc. 10th EUSAR, Jun. 2014, pp. 1-4.

[34] C. Matzler, "Microwave permittivity of dry snow," IEEE Trans. Geosci. Remote Sens., vol. 34, no. 2, pp. 573-581, Mar. 1996.

[35] J. M. Reynolds, An Introduction to Applied and Environmental Geophysics. New York, NY, USA: Wiley, 19997.

[36] H. M. Jol, Ground Penetrating Radar Theory and Applications. Burlington, MA, USA: Elsevier, 2009.

[37] D. J. Daniels, Ground Penetrating Radar, ser. IEE radar, sonar, navigation, and avionics series, 2nd ed. London, U.K.: Inst. Elect. Eng., 2004.

[38] K. J. Langenberg, Applied Inverse Problems for Acoustic, Electromagnetic and Elastic Wave Scattering, in Basic Methods of Tomography and Inverse Problems, P. C. Sabatier, Ed. Bristol, U.K.: Adam Hilger, 1987.

[39] A. C. Kak and M. Slaney, Principles of Computerized Tomographic Imaging. New York, NY, USA: IEEE Press, 1998.

[40] A. Devaney, Inverse Methods in Electromagnetic Imaging. Dordrecht, The Netherlands: Springer-Verlag, 1985.

[41] D. A. Waltham, "Two-point ray tracing using Fermat's principle," Geophys. J., vol. 93, pp. 575-582, 1998.

[42] A. Elsherbini and K. Sarabandi, "Image distortion effects in SAR subsurface imaging and a new iterative approach for refocusing and coregistration," IEEE Trans. Geosci. Remote Sens., vol. 52, no. 5, pp. 2994-3004, May 2014

[43] A. Ishimaru, Wave Propagation and Scattering in Random Media, vol. 2. New York, NY, USA: Academic, 1978. 